
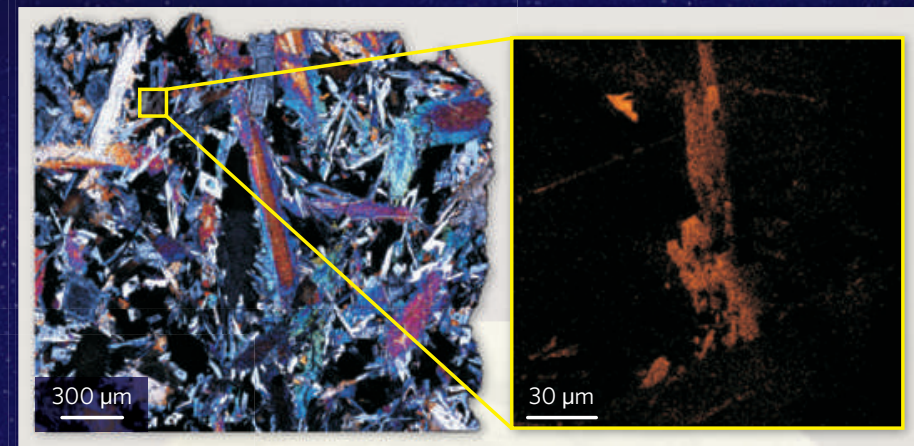

Apollo 15

A grain of the mineral apatite

shows off

rainbow hues

under a

microscope.

Locked inside are

hydroxyl ions

(orange, inset)

revealing the

presence of

water.

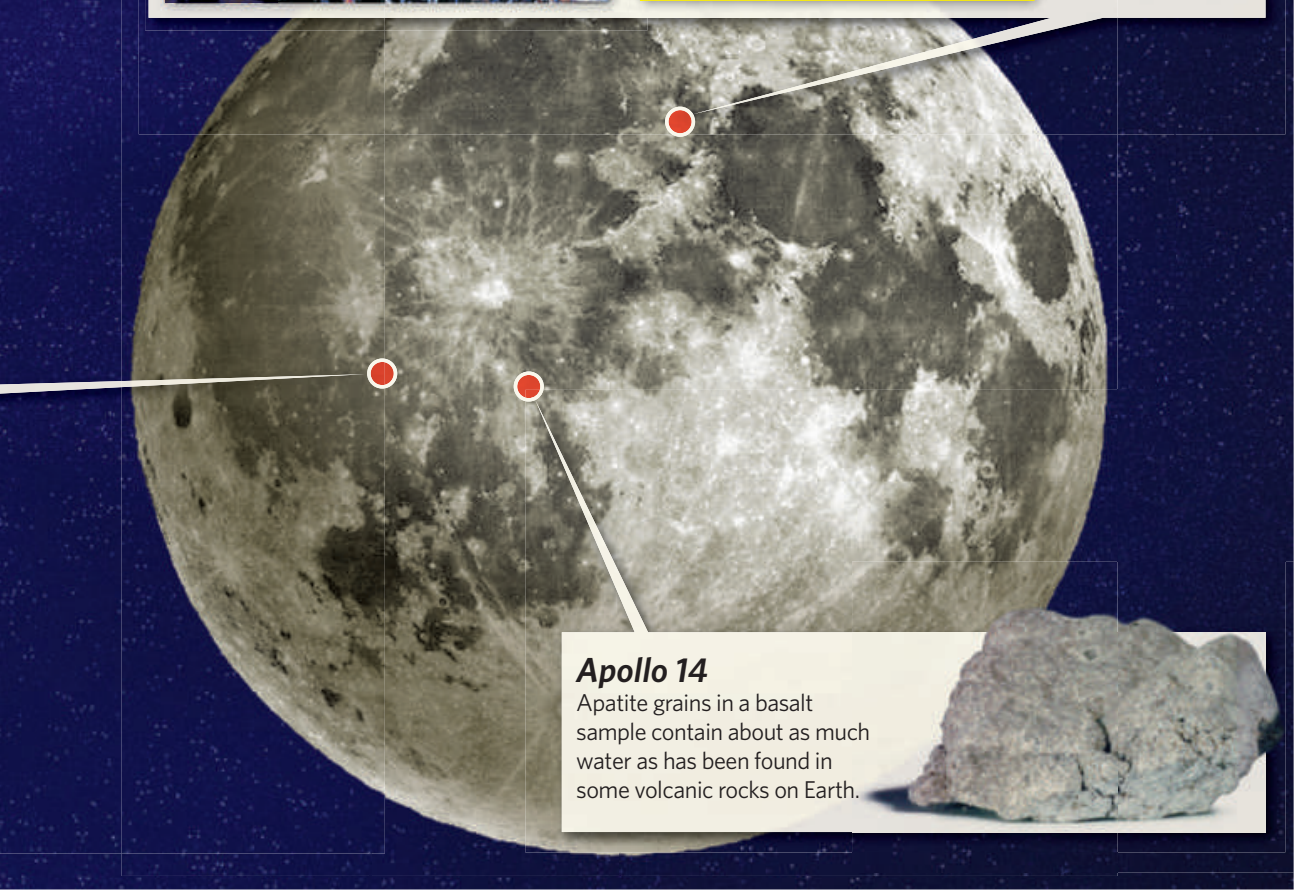

for its formation, and that the heavy comet water mixed into the Moon's magma ocean. The comets would have struck Earth too, but because the young planet had a significantly larger supply of water, the heavy water deposited on Earth was greatly diluted.

Alternatively, perhaps the heat of the impact evaporated the lighter water from the Moon, leaving it enriched in heavier water. Or maybe the impactor itself contained large amounts of heavy water.

According to Elkins-Tanton, "this may all lead to a reconsideration of the giant-impactor theory," especially in how it relates to the origin of lunar water.

But not yet. The heavy-water results could reflect nothing more than a specific spot of enrichment - the impact site of an ancient comet, for example. And some researchers aren't convinced that the Moon is a wet as the new results suggest.

Chip Shearer at the University of New Mexico in Albuquerque has been analysing chlorine in volcanic rocks, which can provide some information about ancient water because of the way chlorine would have bound to it to form other compounds. $\mathrm{He}$ says that the estimated water concentrations reported last week are at the upper limit of the range allowed by his chlorine results.

Sorting out the debate will require new samples. To Clive Neal at the University of Notre Dame in Indiana and chair of a NASA lunar advisory group, that means returning to the Moon. But before then, researchers will be revisiting the rocks collected by Apollo astronauts.

At the meeting last week, Taylor drew an index card out of his wallet that contained the five-digit codes for three more samples he was going to retrieve from the vaults at the Johnson Space Center, on the other side of Houston from the conference. He has made the trip many times before. "Being an old fart," he says, "I know the ropes."

Eric Hand

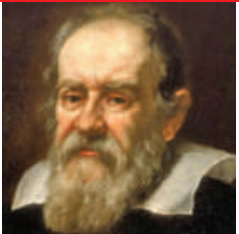

GALILEO BACKED COPERNICUS DESPITE DATA

Early telescopes suggested that Earth stood still.

go.nature.com/OV49Sv

\section{Biology thinks big to stay cuts}

Biologists with grandiose research proposals often turn to the risk-tolerant Human Frontier Science Program (HFSP) to get themselves started. However, the world's only intercontinental research funding agency is now working hard to convince its members -13 individual nations plus representation from the European Union - that frontier research is a wise investment in tough economic times. The 20-year-old HFSP distributes about US\$60 million a year to support research into complex biological systems. Last week, the programme's secretary-general, geneticist Ernst-Ludwig Winnacker, met with an elite group of about two dozen scientists to discuss where the frontiers of biology might lie.

Participants agreed that genetic technologies will continue to be central to frontier biology; that fields such as microscopy will continue to drive it; and that new developments in chemistry will feed it. Tom Henzinger of the Institute of Science and Technology in Vienna also convinced participants that pure mathematics could become an increasingly useful tool in understanding biological processes.

"We remain open to any approach — the three sole criteria remain excellence, risk and biology," says Winnacker, who has previously served as secretary-general of the European Research Council and president of the German research agency the DFG.

The general messages from the brainstorming session will feed into the organization's first formal strategy report, which will be crucial when the HFSP's members meet in May. Winnacker is already bracing himself for trouble: Japan, which normally contributes around half of the budget, has this year cut its contribution by $5 \%$, and the global financial crisis is squeezing all members. Winnacker hopes that the report will help to secure continued funding for this unique programme, whose unbureaucratic support of big ideas is popular with scientists. "It is a paradox that science is international, but funding is regional or national," Winnacker notes. "The HFSP is the only agency with none of the political borders that make joint funding so complicated." 